IOS Press

\title{
Relationship between plant architecture and fruit production of the short-day strawberry cultivar Gariguette ${ }^{1}$
}

\author{
Jean-Philippe Bosc ${ }^{\mathrm{a}, *}$, Davide Neri ${ }^{\mathrm{b}}$, Francesca Massetani $^{\mathrm{b}}$ and Alain Bardet ${ }^{\mathrm{c}}$ \\ ${ }^{\mathrm{a}}$ Ctifl, Technical Institute for Fruits and Vegetables, Bellegarde, France \\ ${ }^{\mathrm{b}}$ D3A - Department of Agricultural, Alimentary and Environmental Science, Faculty of Agriculture, \\ Università Politecnica delle Marche, Ancona, Italy

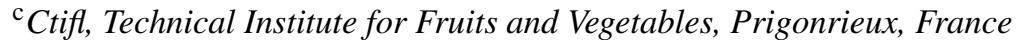

Received 10 November 2011; accepted 10 December 2011

\begin{abstract}
This research was carried out to assess the relationship between the architecture of strawberry plants before chilling and winter-spring fruit production in a soilless forced culture system. On 11 September 2008, trayplants of the cultivar Gariguette were placed in a heated glasshouse and either exposed to long-day photoperiodic conditions or short-day photoperiodic conditions for 53 days. In addition, plants were held 26 days under short-day photoperiodic conditions followed by 27 days of long-day photoperiodic conditions or 26 days under long-day photoperiodic conditions followed by 27 days of short-day photoperiodic conditions. Architecture prior to chilling gave indications about the first fruit production period in winter-spring (1 March to 30 April 2009). The earliest short-day photoperiodic condition treatments produced the earliest fruits. These treatments exhibited the most developed inflorescences in the pre-chilling architectural analysis and the fewer nodes between the youngest expanded leaf and the terminal inflorescence. The plants that received 53 days of long-day photoperiodic conditions treatment had the least developed terminal inflorescence before chilling and the latest production. The architecture analysis of Gariguette trayplants could predict the earliness rank (first to last) but not the yield rank during the first harvest period.
\end{abstract}

Keywords: Fragaria x ananassa, photoperiod, trayplant, soilless production, nursery

\section{Introduction}

In France, soilless cultivation of strawberry is used to produce high quality and tasty fruit, and heating conditions enable the harvest to start in February. This production system is commercially competitive with Spanish and Moroccan production. The short-day cultivar Gariguette, well-known by the French consumers, is the most cultivated variety in this French soilless production system. Because of the high cost of equipment and inputs, soilless heated cultivation is economically viable only for high and early yield crops whereas type and quality of propagated plants are key points for a successful crop yield. Trayplants are becoming more popular as they are less susceptible to problems associated with adverse winter climatic conditions [1]. Trayplant culture techniques must provide however adequate floral induction in autumn for optimal fruit production (yield, earliness) and quality during winter and spring.

\footnotetext{
${ }^{1}$ Paper presented at 28th International Horticulture Congress, IHC 2010, Lisbon, Portugal.

${ }^{*}$ Corresponding author: Jean-Philippe Bosc, Ctifl, 751 Chemin de Balandran, 30127 Bellegarde, France. Tel.: +33 46601 10 54; Fax: +33 466 0162 28; E-mail: bosc@ctifl.fr.
} 
Numerous publications deal with the effects of photoperiod, temperature and nutrition on flowering [2-8] but few take into account the effects on the architecture of the plant [9-12]. These publications demonstrated the considerable environmental variability of floral induction among cultivars and cultivation techniques. This research was carried out to assess whether the plant's architecture analysis can be used to predict the winter-spring fruit production of a soilless heated crop prior to chilling trayplants. Trayplants of Gariguette were subjected to different short/long day conditions in autumn to affect plant architecture before chilling, earliness to harvest, and fruit yields.

\section{Materials and methods}

Homogeneous plants of Gariguette cultivar grown in commercial trayplant trays were obtained from a commercial nursery batch (Darbonne SAS Nursery) on 2 September and placed from 2 September to 11 September 2008 in an outdoor nursery at the Ctifl Balandran Centre (Southern France, Mediterranean conditions, $04^{\circ} 28^{\prime} \mathrm{E}-43^{\circ} 45^{\prime} \mathrm{N}$ ). Natural light was extended $22 \mathrm{~h} /$ day by incandescent lamps (photon flux density $\sim 5 \mu \mathrm{mol} \mathrm{m}^{-2} \mathrm{~s}^{-1}$ PAR at leaf level) to maintain the plants under long-day conditions. On 11 September, trayplants were placed in a heated glasshouse and either exposed to long-day photoperiodic conditions or short-day photoperiodic conditions for 53 days. In addition, plants were held 26 days under short-day photoperiodic conditions followed by 27 days of long-day photoperiodic conditions or 26 days under long-day photoperiodic conditions followed by 27 days of short-day photoperiodic conditions. Short-day conditions received only natural daylight while long-day conditions were achieved by daylight extension to $22 \mathrm{~h}$ /day with "coolwhite" fluorescent lamps (Sylvania T8 standard F58W/133; photon flux density $\sim 25 \mu \mathrm{mol} \mathrm{m}{ }^{-2} \mathrm{~s}^{-1} \mathrm{PAR}$ at leaf level). Temperature was semi-controlled and ranged from $14^{\circ} \mathrm{C}$ minimum to $28^{\circ} \mathrm{C}$ maximum. Plants were fertilised daily with a complete fertilisation solution $\left(\mathrm{EC} 1.2 \mu \mathrm{S} \mathrm{cm}^{-1}\right)$. From 3 November to 8 December, all plants were placed in a dark cold room $\left(2^{\circ} \mathrm{C}\right)$ for storage in chilling conditions, after which they were planted in a forced soilless culture system for fruit production (heated plastic tunnel).

\subsection{Plant architecture}

\subsubsection{Before chilling}

Just before chilling ( 3 November), fifteen plants per treatment were sampled and dissected under a stereomicroscope ( $\times 40$ magnification) to determine their plant architecture, i.e. the number of differentiated or vegetative apices, inflorescences and leaves, and their position along the stems. The inflorescence developmental stages at the apical meristems of each position along the stem were assessed according to Jahn and Dana [13] and subsequent modifications as described by Savini [14] and Savini et al. [10]: $0=$ vegetative apex; $1=$ primary flower primordium; $2=$ sepal initiation on primary flower; $3=$ petal initiation on primary flower; $4=$ sepals and petals are developed; $5=$ stamen formation on primary flower; $6=$ primary flower is enclosed by sepals and epidermal hairs are initiated; $7=$ primary flower is completed with green anthers; $8=$ primary flower with yellow anthers; $9=$ completely formed cluster. Graphic models were made.

\subsubsection{Before fruit production}

At the end of chilling, 20 plants per treatment were sampled. The youngest expanded leaf was identified with a label. These plants were cropped separately but in the same conditions as plants for fruit production and removed on 26 February (just before fruit production began). The position of leaves (petiole longer than $1 \mathrm{~cm}$ long), branches, and inflorescences (longer than $1 \mathrm{~cm}$ long) was determined based on the youngest expanded leaf and graphic models were drawn.

\subsection{Fruit production}

In the soilless culture system, treatments were arranged in a four replicate complete block design of 16 plants per plot. Plants were placed in plastic boxes with a density of 4 plants/linear meter. The substrate was a commercial 
mix of peat and composted pine bark (Dumona 16/6). Fruits were picked twice a week, weighed and counted from 2 March until 30 April.

\section{Results}

\subsection{Plant architecture before chilling}

The plants exposed early to short-day conditions, either lasting for 53 or 26 days exhibited less developed primary branches (e.g. fewer nodes and leaves inside the primary branch terminal bud), a more differentiated inflorescence at the shoot apical meristem and more inflorescences on the top portion of the primary branch, in comparison with the plants of the early long-day photoperiodic treatments (Table 1). Also, at least one secondary branch was visible just under the terminal inflorescence of the primary branch of plants that received early short-day photoperiodic treatments (Fig. 1). None of the plants with 53 days of long-day photoperiodic conditions and a low proportion of plants with 26 days long-day followed by 27 days short-day photoperiodic conditions had a differentiated secondary branch.

\subsection{Plant architecture before fruit production}

Plant dissection just before fruit production revealed that all the plants had one or two secondary branches and the majority of them had also one or two tertiary branches. The inflorescences had developed from all the primary and secondary branches after 53 days of long-day or 26 days of long-day followed by 27 days short-day photoperiodic treated plants (Fig. 2). Among the leaves that were present on the primary branch before chilling, only the youngest expanded leaf remained and the older leaves had become senescent.

The early treatments with short-day conditions ( 53 days of short-day, 26 days of short-day followed by 27 days of long-day) had similar numbers of expanded leaves, secondary branches, visible inflorescences and nodes between the most developed inflorescence and the youngest expanded leaf before chilling (Table 2). Both these treatments induced a greater number of expanded leaves, visible inflorescences and nodes between youngest expanded leaf before chilling and primary inflorescence than early treatments with long days.

The details of the architecture showed some differences between 53 days of short-day photoperiodic conditions and 26 days of short-day followed by 27 days of long-day treatments (Fig. 2). In both treatments 4 inflorescences were present in nearly $25 \%$ the plants. Two secondary branches with an inflorescence was observed in $75 \%$ of plants treated with short-day photoperiodic conditions continuously for 53 days, but in only $55 \%$ of plants from 26 days of short-day followed by 27 days of long-day photoperiodic conditions. In both treatments, the secondary branches had two or three nodes subtending the inflorescence, showing that their induction occurred rapidly after the induction of the primary branch terminal inflorescence. Three plants (among 20 plants dissected) from the 26 days of shortday followed by 27 days of long-day photoperiodic conditions treatment had only two visible inflorescences, one secondary (bearing an inflorescence) and one tertiary branch.

Table 1

Effect of photoperiodic treatments from September 9th to November 3rd on plant architecture on November 3rd

\begin{tabular}{|c|c|c|c|c|}
\hline $\begin{array}{l}\text { Photoperiodic } \\
\text { conditions }\end{array}$ & $\begin{array}{l}\text { No. of nodes on } \\
\text { primary branch }\end{array}$ & $\begin{array}{c}\text { No. of unexpanded } \\
\text { leaves on primary branch }\end{array}$ & $\begin{array}{l}\text { Terminal inflorescence } \\
\text { stage }\end{array}$ & $\begin{array}{l}\text { No. of inflorescence } \\
\text { at the shoot apical bud }\end{array}$ \\
\hline 53 days of short-day & $13.9 b^{1}$ & $4.0 \mathrm{~b}$ & $6.2 \mathrm{a}$ & $1.2 \mathrm{a}$ \\
\hline 26 days of short-day +27 days of long-day & $14.0 \mathrm{~b}$ & $3.4 \mathrm{~b}$ & $6.1 \mathrm{a}$ & $1.3 \mathrm{a}$ \\
\hline 26 days of long-day +27 days of short-day & $16.2 \mathrm{a}$ & $5.6 \mathrm{a}$ & $3.7 \mathrm{~b}$ & $0.2 \mathrm{~b}$ \\
\hline 53 days of long-day & $16.3 \mathrm{a}$ & $6.1 \mathrm{a}$ & $1.8 \mathrm{c}$ & $0.1 \mathrm{~b}$ \\
\hline
\end{tabular}

${ }^{1}$ Different letters denote statistical difference. $p=0.05$. 


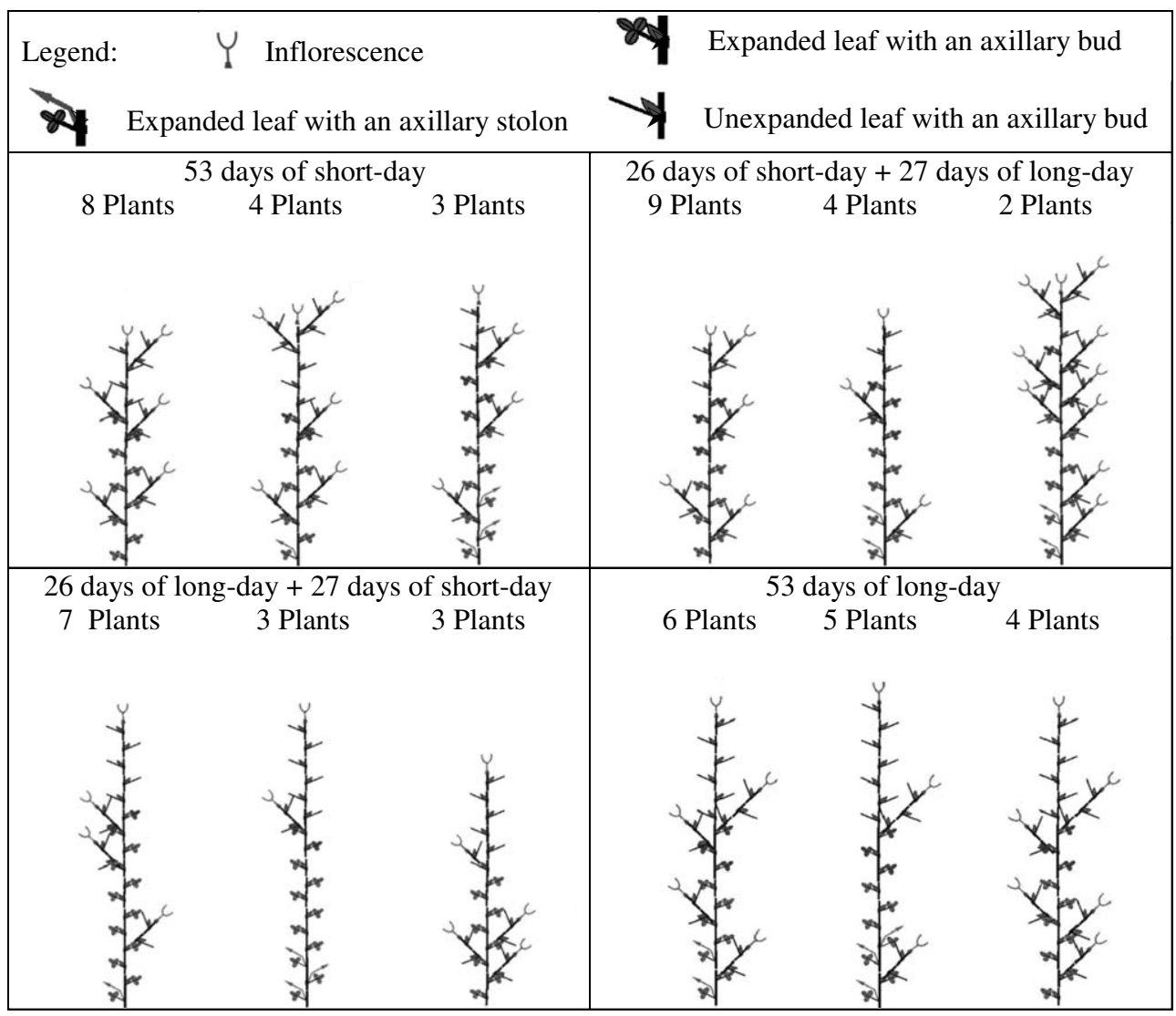

Fig. 1. Effect of photoperiodic treatments applied from September 9th to November 3rd on plant architecture analyzed on November 3rd (15 plants).

The early treatments with long days (53 days of long-day photoperiodic conditions, 26 days of long-day followed by 27 days of short-day photoperiodic conditions) induced less flower differentiation. None of the plants had developed four visible inflorescences, and the proportion of plants with two secondary branches with an inflorescence seems fewer (Table 2). In both treatments, 11 and 15 plants respectively (out of 20) bore two visible inflorescences. Plants from the 26 days of long-day followed by 27 days of short-day photoperiodic conditions treatment developed only two secondary branches from the lateral buds just under the inflorescence of the primary branch. Six of the plants from 53 continuous days of long-day photoperiodic conditions treatment developed four secondary branches, but an inflorescence was not visible on these secondary branches.

\subsection{Fruit production}

Fruit production from the first bloom occurred from 2 March to 30 April. Considering the timing of production (Fig. 3), the four treatments regularly increased production during March to reach an approximate level of $30 \mathrm{~g} / \mathrm{plant}$ per picking, on an earlier or later date, depending on the treatments: on the earliest date for the early short-day treatments and on the latest date for the 53 days of long-day treatment (Table 3).

Higher cumulative yields were obtained with 53 days of short-day treatment than with 53 days of long-day treatment (Table 3). Short-day conditions followed by long-day conditions led to intermediate yields that were not statistically different from those of the previous treatments. The lowest yield was provided by the 26 days of long-day followed by 27 days of short-day photoperiodic conditions. 




Fig. 2. Effect of photoperiodic treatments applied from September 9th to November 3rd on plant architecture analyzed on February 26th (20 plants).

Table 2

Effect of photoperiodic treatments from September 9th to November 3rd on plant architecture on February 26th

\begin{tabular}{|c|c|c|c|c|}
\hline Photoperiodic conditions & $\begin{array}{c}\text { No. of nodes between } \\
\text { the tagged leaf and } \\
\text { the primary } \\
\text { inflorescence }\end{array}$ & $\begin{array}{l}\text { No. of visible } \\
\text { inflorescences/ } \\
\text { plant }\end{array}$ & $\begin{array}{c}\text { No. of expanded } \\
\text { leaves/plant }\end{array}$ & $\begin{array}{l}\text { No. of plants with only two } \\
\text { secondary branches } \\
\text { bearing an inflorescence } \\
\text { (20 plants) }\end{array}$ \\
\hline 53 days of short-day & $3.8 \mathrm{~b}^{1}$ & $3.3 \mathrm{a}$ & $13.0 \mathrm{~b}$ & 15 \\
\hline $\begin{array}{l}26 \text { days of short-day }+27 \\
\text { days of long-day }\end{array}$ & $4.0 \mathrm{~b}$ & $3.0 \mathrm{a}$ & $12.1 \mathrm{~b}$ & 11 \\
\hline $\begin{array}{l}26 \text { days of long-day }+27 \text { days } \\
\text { of short-day }\end{array}$ & $6.0 \mathrm{a}$ & $2.2 \mathrm{~b}$ & $15.7 \mathrm{a}$ & 6 \\
\hline 53 days of long-day & $6.5 \mathrm{a}$ & $2.3 \mathrm{~b}$ & $16.8 \mathrm{a}$ & 7 \\
\hline
\end{tabular}

${ }^{1}$ Different letters denote statistical difference. $p=0.05$. 


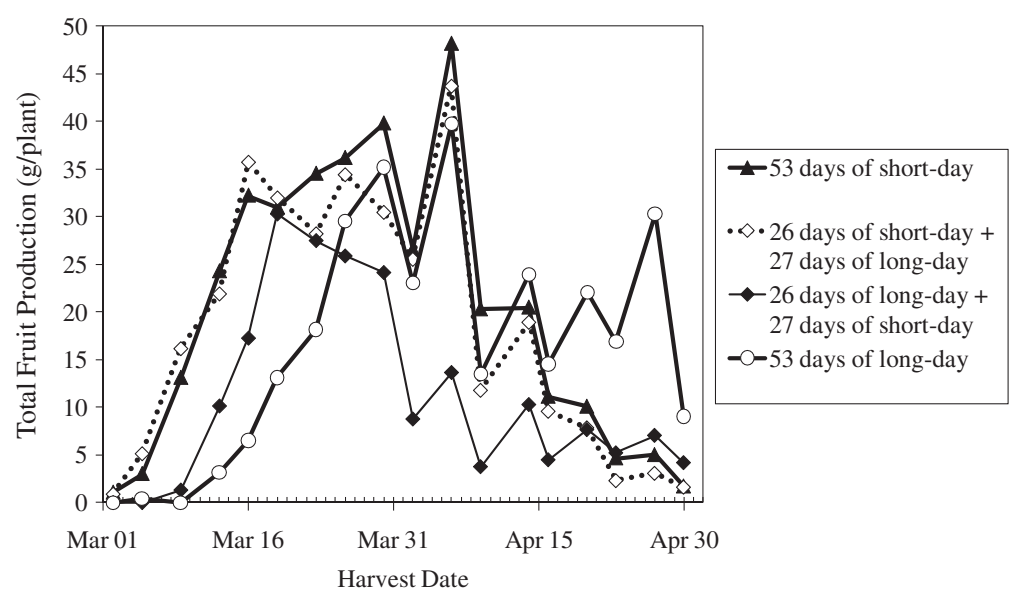

Fig. 3. Effect of photoperiodic treatments on fruit yields from March to April.

Table 3

Effect of photoperiodic treatments from September 9th to November 3rd on fruit production in March and April

\begin{tabular}{|c|c|c|c|c|}
\hline \multirow[t]{2}{*}{ Photoperiodic conditions } & \multicolumn{3}{|c|}{ Fruit production (g/plant) } & \multirow{2}{*}{$\begin{array}{l}\text { Total cumulative fruit } \\
\text { production (g/plant) }\end{array}$} \\
\hline & On 16 March & On 19 March & On 23 March & \\
\hline 53 days of short-day & $32.2 \mathrm{a}$ & $31.0 \mathrm{a}$ & $34.5 \mathrm{a}$ & $363 \mathrm{a}^{1}$ \\
\hline $\begin{array}{l}26 \text { days of short-day }+27 \\
\text { days of long-day }\end{array}$ & $35.8 \mathrm{a}$ & $32.0 \mathrm{a}$ & $28.2 \mathrm{ab}$ & $330 \mathrm{ab}$ \\
\hline $\begin{array}{l}26 \text { days of long-day }+27 \text { days } \\
\text { of short-day }\end{array}$ & $17.3 \mathrm{~b}$ & $30.3 \mathrm{a}$ & $27.5 \mathrm{ab}$ & $202 \mathrm{c}$ \\
\hline 53 days of long-day & $6.5 \mathrm{~b}$ & $13.1 \mathrm{~b}$ & $18.2 \mathrm{~b}$ & $299 \mathrm{~b}$ \\
\hline
\end{tabular}

${ }^{1}$ Different letters denote statistical difference. $p=0.05$.

\section{Discussion}

On all treatments, the rudimentary secondary branches that had formed below the youngest expanded leaf (e.g. "frontier" leaf) prior to chilling (dark cold storage conditions) did not have any further role in plant development, whereas those secondary branches that formed above the "frontier" leaf were able to continue their growth and differentiation. Therefore all the secondary and tertiary branches which were present before fruit production developed above the "frontier" leaf. The secondary branches were present before chilling as differentiated axillary buds that developed into extension crowns and bore the second and third inflorescences of the crown $[10,15]$.

In most plants that were exposed early to short-day treatments, the secondary branches that developed in February were already visible in November. The tertiary branches which were present in February were not visible in November. In plants exposed early to long-day treatments two secondary branches developed after chilling from the latent lateral meristems, just under the terminal inflorescence.

The architecture before chilling was predictive for the future position of the secondary branches in February if, before chilling, they were already at an early stage of differentiation and above the "frontier" (last expanded) leaf. On treatments early exposed to long days, secondary branches with inflorescences that were visible in February suggested that their initiation happened after chilling, as these branches were not differentiated before. In these treatments all the tertiary branches were formed after chilling and, when visible in February, did not bear inflorescences.

An assessment of plant crown development by plant architectural analysis before chilling was a good predictor of fruit production earliness, i.e. the order in which the plants came into production [14]. The earliest fruit production was achieved by the early short-day treatments [16] exhibiting, prior to the period of chilling, the most developed 
terminal inflorescence, the least number of nodes inside the primary branch terminal bud (53 days of short-day photoperiodic conditions, 26 days of short-day followed by 27 days of long-day photoperiodic conditions) and, on most of these plants, at least one of the two secondary branches that will bear a fruiting inflorescence in February. In contrast, fruit production was late for the treatment (53 days of long-day photoperiodic conditions) presenting, before chilling, the least developed terminal inflorescence, a greater number of nodes and no secondary branches inside the terminal bud. The intermediate treatment for fruit production earliness ( 26 days of long-day followed by 27 days of short-day photoperiodic conditions treatment) was also intermediate for the development stage of the terminal inflorescence.

Nonetheless, plant architectural analysis gave far less predictive information about total fruit production in March and April, that is determined by flower induction after chilling and by the number of flowers per inflorescence [14, 17]. The treatments exposed early to long days (53 days of long-day photoperiodic conditions, 26 days of longday photoperiodic followed by 27 days of short-day photoperiodic conditions) showed similar structure leading to different fruit yields. Furthermore, cumulative fruit yield was not different for the 26 days of short-day followed by 27 days of long-day photoperiodic conditions treatment and the 53 days of long-day photoperiodic conditions treatment, although they exhibited two different plant structures before chilling.

In conclusion, in our experimental conditions, the analysis of the architecture of Gariguette trayplants predicted the order in which the plants came into production, but could not predict the total yield rank (first to last) during March and April, possibly because the production happened on the branches that were formed (all the tertiary branches) or developed (secondary branches) after the cold storage.

\section{References}

[1] P. Lieten, Strawberry production in central Europe, International Journal of Fruit Science 5 (2005), 89-103.

[2] S. Serçe and J.F. Hancock, The temperature and photoperiod regulation of flowering and runnering in the strawberries, Fragaria chiloensis, F virginiana, and F. x ananassa. Scientia Horticulturae 167(103) (2005), 167-177.

[3] M.J. Verheul, A. Sønsteby and S.O. Grimstad, Interaction of photoperiod, temperature, duration of short-Day treatment and plant age on flowering of Fragariax ananassa Duch. cv. Korona, Scientia Horticulturae 164(107) (2006), 164-170.

[4] A. Sønsteby and O.M. Heide, Dormancy relations and flowering of the strawberry cultivars Korona and Elsanta as influenced by photoperiod and temperature, Scientia Horticulturae 57(110) (2006), 57-67.

[5] A. Yamasaki and T. Yano, Effect of supplemental application of fertilizers on flower bud initiation and development of strawberry-possible role of nitrogen, Acta Horticulturae 842 (2009), 765-768.

[6] A. Sønsteby, N. Opstad, U. Myrheim and O.M. Heide, Interaction of short day and timing of nitrogen fertilization on growth and flowering of 'Korona' strawberry (Fragaria x ananassa Duch), Scientia Horticulturae 123 (2009), 204-209.

[7] A. Sønsteby and O.M. Heide, Temperature responses, flowering and fruit yield of the June-bearing strawberry cultivars Florence, Frida and Korona, Scientia Horticulturae 119 (2008), 49-54.

[8] N. Opstad, A. Sønsteby, U. Myrheim and O.M. Heide, Seasoal timing of floral initiation in strawberry: Effects of cultivar and geographic location 129 (2011), 127-134.

[9] G. Savini, A. Letouzé, C. Sabbadini and D. Neri, Evaluation of tray-plant quality in the propagation phase, Acta Horticulturae 231(708) (2006), 231-236.

[10] G. Savini, D. Neri and F. Zucconi, N. Sugiyama, Strawberry growth and flowering, an architectural model, International Journal of Fruit Science 27(5(1)) (2005), 29-50.

[11] G. Savini and D. Neri, Strawberry architectural model, Acta Horticulturae 169(649) (2004), 169-176.

[12] M. Chatterjee, C.L. Bermudez-Lozano, M.A. Clancy, T.M. Davis and K.M. Folta, A strawberry KNOX gene regulates leaf, flower and meristem architecture, PLoS ONE 6(9) (2011), e24752.

[13] O.L. Jahn and M.N. Dana, Crown and inflorescence development in the strawberry, Fragaria X Ananassa, American Journal of Botany $\mathbf{6 0 5}(57(6))$ (1970), 605-612.

[14] G. Savini, Schema architetturale e fattori implicati nella differenziazione a fiore della fragola (Fragaria X ananassa Duch.) (Architectural model and factors implicated in the flower differentiation of strawberry plants). Ph. D. Thesis, Marche Polytechnic University, 2003 , pp. 151.

[15] T. Kurokura, Y. Inaba, D. Neri and N. Sugiyama, A morphological study of the development of the second inflorescences in strawberry (Fragaria x ananassa Duch), Annals of Applied Biology 146 (2005), 511-515.

[16] H. Ito and T. Saito, Studies on the flower formation in the strawberry plants. I. Effects of temperature and photoperiod on the flower formation, Tohoku Journal of Agricultural Research 13 (1962), 191-203.

[17] A. Jemmali and P. Boxus, Early estimation of strawberry floral intensity and its improvement under cold greenhouse, Acta Horticulturae 348 (1993), 357-360. 